\title{
THE EFFECT OF SHIP SHAPE AND ANEMOMETER LOCATION ON WIND SPEED MEASUREMENTS OBTAINED FROM SHIPS
}

\author{
B I Moat and M J Yelland, Southampton Oceanography Centre, UK \\ A F Molland, School of Engineering Sciences, Ship Science, University of Southampton, UK \\ R W Pascal, Southampton Oceanography Centre, UK
}

\section{SUMMARY}

Wind speed measurements obtained from ship-mounted anemometers are biased by the distortion of the airflow around the ship's hull and superstructure. These wind speed measurements are used both in numerical weather prediction and in climate studies and need to be known as accurately as possible. This paper presents results from CFD models used to quantify and correct airflow distortion effects.

Three-dimensional CFD studies of the mean airflow over various research ships and a generic tanker/bulk carrier have been performed. The bias in the wind speed measurements is highly dependent upon anemometer position and ship shape. Even for anemometers in well-exposed locations on research ships the wind speed may be biased by about $10 \%$. Anemometers located above the bridge of tankers/bulk carriers may not be as well exposed and could be accelerated by over $10 \%$ or decelerated by $100 \%$.

CFD results are compared to in situ wind speed measurements made from a number of anemometers above the bridge of the research ship RRS Charles Darwin. The CFD-predicted wind speeds agreed with those measured to within $4 \%$.

\section{INTRODUCTION}

Several thousand merchant ships are recruited to the World Meteorological Organisation (WMO) Voluntary Observing Ship (VOS) programme to report the meteorological conditions at the ocean surface. These reports include wind speed and direction, air and sea surface temperature, cloud cover and sea state. Wind speed measurements obtained from anemometers on these ships are biased by the distortion of the airflow by the ships hull and superstructure. Quantifying this bias is important for accurate wind speed measurements needed for ocean/atmosphere model forcing, satellite validation and for climate change studies. Previous studies have been carried out to investigate flow over ship superstructures in respect of smoke dispersion $[1,2]$ or over the aft deck of warships for landing helicopters [3, 4]. The current work focuses on studying the general flow pattern over ship's superstructures with particular attention to the correction of wind speed measurements made from fixed anemometers.

Computational fluid dynamics (CFD) has been employed to correct the wind speed measurements obtained from research ships [5 to 10]. Kahma and Leppäranta [5] applied potential flow theory to model the flow over a 2dimensional ship model. Potential flow models simulate the flow of an ideal fluid and do not reproduce many features of a real flow, e.g. flow separation. Nevertheless, their study gave the first insight into the magnitude of the flow distortion at anemometer sites on ships. With the increase in computing power more realistic flow models have recently been used. Yelland et al. [6, 7] used the 3dimensional CFD code VECTIS to predict the airflow distortion at anemometer sites on a number of research ships. Dupuis [8] used a 3-dimensinal CFD model and predicted wind speed increases of about $20 \%$ at the main mast site on the RV L'Atalant. Popinet et al. [9] used the Large Eddy Simulation code GERRIS [10] to study the unsteady flow around the R/V Tangaroa. In all cases the ship geometries were very detailed.

This paper will describe the CFD code VECTIS (Section 2). In situ measurements used to validate the CFD simulations will be described in Section 3. Results from previous flow simulations over the RRS Charles Darwin (Figure 1) and RRS Discovery (Figure 2) will be used to highlight the changes in wind speed created by the presence of research ships (Section 4.1). In addition recommendations will be made on locating anemometers to minimise the effects of flow distortion in wind speed measurements.

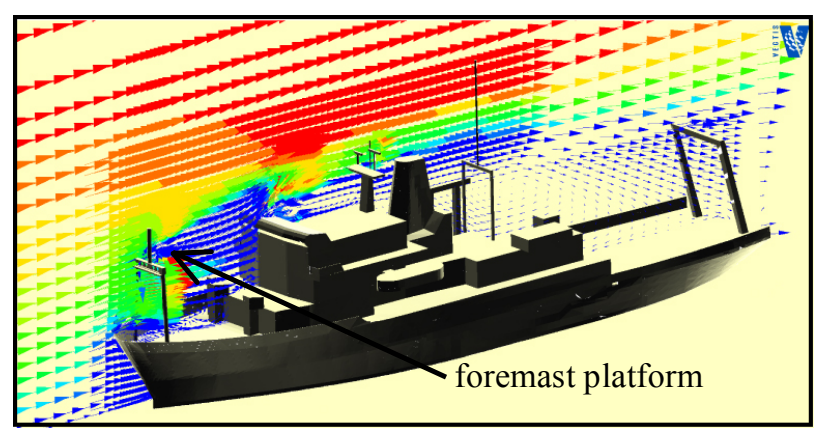

Figure 1:The airflow directly over the bow of the RRS Charles Darwin. The shade of the velocity vectors represents the speed of the flow.

Section 4.2 will describe the work of Moat et al. [11, 12] in studying the airflow over a typical tanker/bulk carrier (Figure 3). The problems associated with simulating the airflows over a container ship will be discussed in Section 4.3. The results of these studies will be used to 
make recommendations for locating anemometers on ships (Section 5).

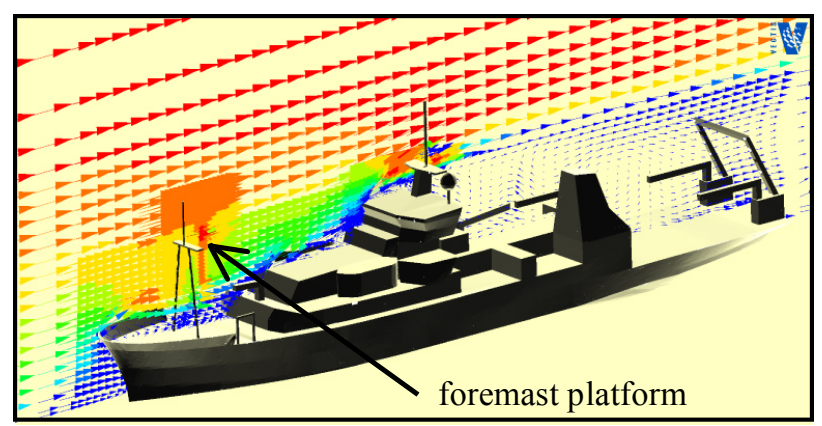

Figure 2: As Figure 1, but for a flow over the RRS Discovery.

\section{COMPUTATIONAL METHOD}

The CFD simulations were performed using the VECTIS software package [13]. VECTIS is a commercial threedimensional Reynolds Averaged Navier-Stokes solver originally designed to study the fluid flow within engines. Nevertheless, the code has successfully been used since 1993 to model the airflow over many research ships [6, 7]. The benefit of using VECTIS over other commercial codes is the speed at which the mesh can be created. For complicated geometries typical meshes of 500,000 cells can be created in less than an hour.

The finite volume code VECTIS is second order accurate. The VECTIS studies are only intended to reproduce the steady state mean flow characteristics, not accurate simulations of the turbulence structure. Therefore the standard $k \sim \varepsilon$ [14] and RNG $k \sim \varepsilon$ [15] turbulence closure models were used to approximate the turbulence. Eason [16] showed that the RNG model was generally as accurate as higher order turbulence models in studying the mean airflow over bluff body cubes.

The detailed ship geometries are created from digitised 2-dimsional ship plans. The digitised plans are then converted into a 3-dimensional geometry using the preprocessing software FEMGEN [17]. The creation of the geometry can take up to 2 weeks. A computational domain is defined around the geometry with the ship in the centre. The size of the domain is dependent upon the ship size and its orientation to the flow. For flows directly over the bow (head to wind) typical domain sizes are $600 \mathrm{~m}$ in length, $300 \mathrm{~m}$ wide and $150 \mathrm{~m}$ high for a ship of $90 \mathrm{~m}$ in length. The width of the domain can increase to over $1000 \mathrm{~m}$ for flows over the ship's beam. In general the ratio of the frontal area of the ship to the area of the inlet provides a blockage by the ship of less than $1 \%$.

VECTIS is based on a regular Cartesian mesh within which the number of cells can be increased in regions of interest, such as anemometer locations, and around sharp edges. The exact shapes of the geometries are preserved in the mesh generation process. 'Law of the wall' functions were used to describe the thin boundary layers close to surfaces. The computational cells close to the solid surfaces were sub-divided to increase the mesh resolution. The problems associated with regular Cartesian grids and properly resolving the thin boundary layers close to complex geometries was not an issue for the research ship studies, as the anemometer locations are at a great enough distance from the solid walls $(\approx 2 \mathrm{~m})$ to not be affected by the thin boundary layer formation. For the simulations of flow over the simplified tanker (Figure 3) anemometers may be located close to the bridge top. Therefore the boundary layers were accurately resolved to model the complex flow above the bridge. The $\mathrm{y}+$ value varied between 35 and 300 , where $y+$ is the characteristic wall co-ordinate for the boundary layer.

All VECTIS simulations presented were 3-dimensional and steady state. No attempt was made to accurately model the flow within the unsteady wake regions. The number of computational cells used in the simulations varied from 200,000 to 600,000 . Early simulations were run on an SGI Indigo UNIX workstation and took up to 4 weeks to converge. Current simulations are run on the HPC facility at the Southampton Oceanography Centre. This provides a platform on which flow simulations using three times the number of cells used in the early computations can be run in less than 2 weeks.

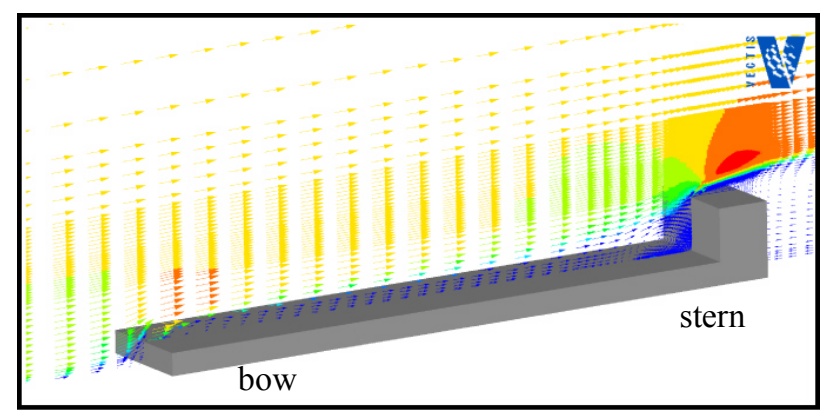

Figure 3: As Figure 1, but for a flow over the simplified tanker geometry.

The inlet wind speed profiles for the research ship studies were defined as atmospheric boundary layers typical of open ocean conditions. The wind speed profile, $U_{Z N}$, varied logarithmically with height, $\mathrm{z}$, and was defined using:

$$
U_{z N}=\frac{u_{*}}{k_{v}} \ln \left(\frac{z}{z_{0}}\right)
$$

where $u_{*}$ is the friction velocity, $k_{v}$ is the von Kármán constant (0.4) and $z_{0}$ is the roughness length. The subscripts 10 and $\mathrm{N}$ refer to a height above the sea surface of $10 \mathrm{~m}$, and equivalent neutral stability conditions. The wind speed profile can be defined from Eq. 1 by calculating values of $u_{*}$ and $z_{0}$. The friction velocity, $u_{*}$, was calculated using:

$$
u_{*}^{2}=C_{D 10 N} U_{10 N}^{2}
$$


where $C_{D 10 N}$ is the drag coefficient which varies with wind speed and is defined by an empirical bulk formula [18]:

$$
1000 C_{D 10 N}=0.61+0.063 U_{10 N}
$$

The roughness length, $z_{0}$, was calculated by combining Eq. 1 and 2 and using a measurement height of $10 \mathrm{~m}$ and specifying the required wind speed at $10 \mathrm{~m}$. Boundary layer profiles and uniform wind speed profiles at typical wind speeds of $7 \mathrm{~ms}^{-1}$ were used in the simulations. Even though the CFD solutions were modelled at sufficiently low wind speeds so that density changes are minimal, a compressible solution was always specified since it produces a more stable solution [19].

VECTIS simulations of the flow over a typical merchant ship (Figure 3) were performed using various mesh densities, turbulence closure schemes, geometry size and inlet wind speed profiles. The results for the changes in the flow field above the ship's bridge are presented in [20] and will be summarised here. The mesh size stated was scaled by the bridge top to deck height, $\mathrm{H}$. The findings showed that there were possible changes in wind speed of $<1 \%$ using minimum cell sizes between $0.018 \mathrm{H}$ and $0.04 \mathrm{H} ;<2 \%$ between the RNG $k \sim \varepsilon$ and standard $k \sim \varepsilon$ turbulence closure schemes; and $<3 \%$ in scaling the geometry. The shape of the wind speed profile has the largest influence (4\%) on the wind speed above the bridge.

\section{VALIDATION OF CFD}

\subsection{COMPARISONS WITH PREVIOUS WIND} TUNNEL DATA

Two test cases were used to validate the VECTIS flow simulations. Both are wind tunnel studies of the flow over surface mounted cubes and were obtained from the European Research Community on Flow, Turbulence and Combustion (ERCOFTAC) database. The first case is a fully developed channel flow [21] and the second is a boundary layer flow [22]. Both sets of measurements were made using a two component Laser Doppler Anemometer (LDA). Comparisons of VECTIS simulations using the standard $k \sim \varepsilon$ and RNG $k \sim \varepsilon$ turbulence closure models are made with the wind tunnel measurements. In all cases the wind speed profiles were normalised by the inlet wind speed. A negative normalised velocity indicates a flow counter to the mean flow direction. All heights were normalised by the height of the surface mounted cube, $\mathrm{H}$, used in the study. The VECTIS simulations are based on a minimum mesh density of $0.02 \mathrm{H}$ above the cube.

The channel flow of Martinuzzi and Tropea [21] was reproduced using VECTIS and are compared to the VECTIS results in Figure 4. The Reynolds number, based on the channel height, was $R_{e}=10^{5}$. The RNG $k \sim \varepsilon$ closure model closely simulates the shape of the accelerated flow region and predicts a maximum increase of $35 \%$, which was reasonably close to the maximum observed in the wind tunnel. The flow in the decelerated region counter to the mean flow direction at heights of $\mathrm{z} / \mathrm{H}<0.2$ is predicted well.

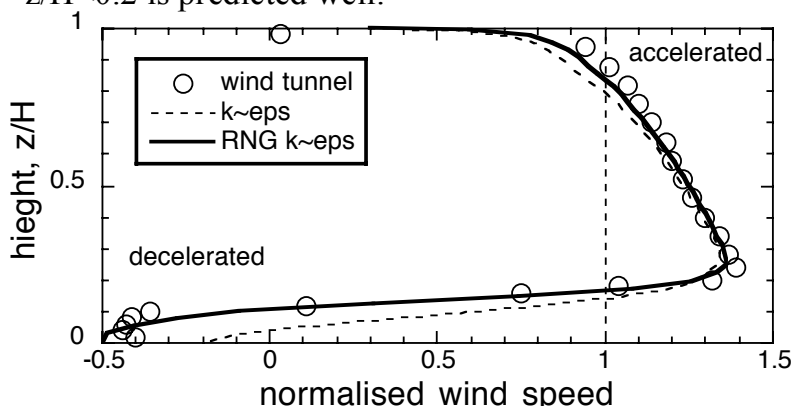

Figure 4 A comparison of VECTIS results with the wind tunnel measurements of [21].

The second test case was the comparison with the boundary layer flow over a surface mounted cube [22]. Measurements of the velocity above the cube are compared to the VECTIS result in Figure 5. The Reynolds number, based on the cube height, was $R_{e}=4 \times 10^{4}$. Unfortunately the measurements were not very extensive with only four measurements between the cube top and height of $\mathrm{z} / \mathrm{H}=0.12$. The $\mathrm{RNG} k \sim \varepsilon$ turbulence closure scheme reproduces the flow pattern in the decelerated region well.

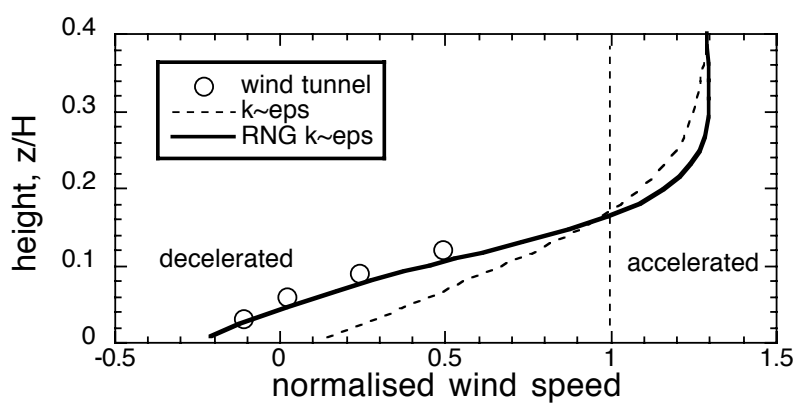

Figure 5 A comparison of VECTIS with the wind tunnel measurements of [22].

\subsection{COMPARISONS WITH IN SITU WIND SPEED DATA}

Wind speed measurements were obtained using anemometers above the bridge of the RRS Charles Darwin (Figure 1) during the SCIPIO cruise [23] in the Indian Ocean. Although not a true representation of the flow over a typical VOS, the ship's structure makes it ideal for studying bluff body flows when the wind is blowing on to either beam. This is a summary of the work described in [24].

Wind speed data were obtained for 58 days between May and July 2002. The ship was equipped with 7 anemometers. A HS sonic was located on the foremast platform. A temporary $6 \mathrm{~m}$ mast equipped with an R2 Sonic anemometer, 4 Vector cup anemometers and a Windmaster sonic anemometer was located above the 
bridge top. The instrument accuracy was: the HS sonic anemometer $\left(< \pm 1 \%\right.$ for winds below $\left.45 \mathrm{~ms}^{-1}\right)$; the R2 sonic anemometer $(<1 \% \mathrm{rms})$; the Windmaster sonic anemometer $\left(1.5 \%\right.$ for winds below $\left.20 \mathrm{~ms}^{-1}\right)$ and the Vector cup anemometers $\left(1 \%, \pm 0.05 \mathrm{~ms}^{-1}\right)$. The HS, R2 and Windmaster sonics output 3-component wind speed measurements at $20 \mathrm{~Hz}, 21 \mathrm{~Hz}$ and $0.1 \mathrm{~Hz}$ respectively. The Vector cup anemometers were sampled at $0.1 \mathrm{~Hz}$.

Pre- and post-cruise calibrations of the HS sonic, R2 sonic and Windmaster sonic were performed to examine any change in the accuracy of the instrumentation during the experiment. The post-cruise HS and Windmaster calibrations showed there was no change in their calibration during the cruise. The post-cruise R2 sonic calibration suggested a $2 \%$ overestimate of the wind speed for relative wind directions over either beam. The correction was applied to the wind speed data measured by this instrument.

An estimate of the free stream, or undistorted, wind speed was required in order to quantify the biases in the measured wind speed for flows directly over either beam. The HS anemometer was used to normalise the wind speed measurements above the bridge because; it was the best-exposed instrument and it was located on the foremast, well away from the bridge top, i.e. the area under investigation. To correct for the effects of airflow distortion at the HS anemometer site CFD simulations of the airflow over both beams of a detailed representation of the RRS Charles Darwin were performed. Corrections of $7.3 \%$ and $3.7 \%$ were applied to the HS sonic in situ wind speed data for flows over the port and starboard beam respectively.

The normalised wind speed profile measured above the bridge of the ship for a flow directly over the port beam is compared to CFD results in Figure 6. Both profiles predict a deceleration in wind speed close to the bridge top and the accelerated region above. In general there is good agreement ( $4 \%$ or better) between the two profiles.

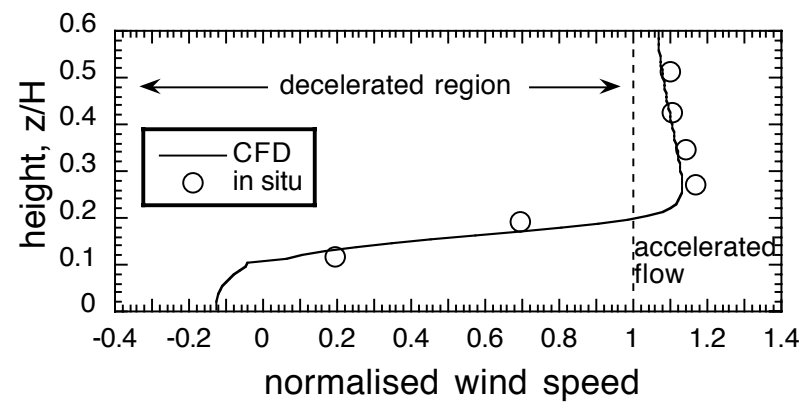

Figure 6: Comparison of $C F D$ and in situ wind speed measurements (adapted from Moat [24]).

\section{CFD RESULTS}

\subsection{RESEARCH SHIPS}

VECTIS simulations of the airflow have been performed over 11 research ships (American, British, Canadian, French and German) [7]. Anemometers on research ships are usually located outside of wake regions and in wellexposed locations, typically on a foremast in the bows of the ship. Even so wind speed data collected from different ships and even data from different instruments on the same ship have disagreed. VECTIS CFD models have successfully been used to correct for this $[6,7]$ and this work will be summarised here.

VECTIS simulations of the air flow over research ships were performed using a full-scale ship with Reynolds numbers varying between $6.81 \times 10^{7}$ to $1.17 \times 10^{8}$, based on the ship length. Wind speed at the anemometer sites are normalised by the free stream, or undisturbed, wind speed at the height of the anemometer. This is obtained from the CFD simulations at a large distance abeam of the anemometer location, typically $250 \mathrm{~m}$ or more. This is important to achieve an absolute bias from the free stream when boundary layer profiles are used.

An example of the wind speed bias present in measurements made from well-exposed anemometers is presented in Figure 7. For these instrument positions, the wind speed measurements can be biased high by up to $7 \%$ and biased low by up to $9 \%$. Other anemometer locations may be biased to a greater extent due to their position relative to the ship superstructure and the platform it is located on.

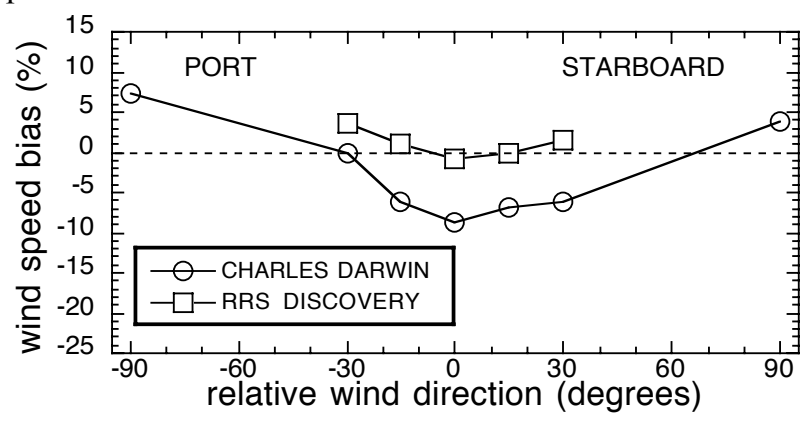

Figure 7: Wind speed bias at well-exposed foremast anemometer sites on two research ships.

The shape of a research ship has a large effect on the amount the airflow is distorted at anemometer sites. For instance, the RRS Discovery (Figure 2) has a streamlined shape with the foremast platform located well away from the bridge superstructure. The wind speed measurements at anemometer sites located on this platform are only decelerated by a few percent. In contrast the foremast on the RRS Charles Darwin is close to a block like superstructure (Figure 1). Consequently these wind speed measurements are decelerated by up to $9 \%$. 
The results of these VECTIS studies have been taken into account in the design of the new UK research ship the RRS James Cook.

\subsection{TANKERS AND BULK CARRIERS}

Little work has been undertaken to quantify the effect of flow distortion on wind speed measurements obtained from anemometers located on VOS. This is due to the several thousand ships participating in the VOS programme making it unrealistic to study each individual ship and the variation in ship type, size and shape. A simple linear model was developed by Moat et al. [11] to describe the principal dimensions of a tanker and bulk carrier. These relationships are very similar to those found more recently by Kent et al. [25] using a much larger sample of ships. In addition, Moat [11] showed that tankers and bulk carriers were similar in shape and, providing that there are no deck cranes present, the same model can describe their principal dimensions. The mean flow over a simplified representation of a tanker/bulk carrier (Figure 3) model of $170 \mathrm{~m}$ was studied. The dimensions of the ship are shown in Table 1.

\begin{tabular}{|c|c|c|c|c|}
\hline $\begin{array}{c}\text { Bridge } \\
\text { to deck } \\
(\mathrm{m})\end{array}$ & $\begin{array}{c}\text { Bridge } \\
\text { to sea } \\
(\mathrm{m})\end{array}$ & $\begin{array}{c}\text { Bridge } \\
\text { length } \\
(\mathrm{m})\end{array}$ & Freeboard & Breadth \\
\hline 13.5 & 19.4 & 13.5 & 5.9 & 27.3 \\
\hline
\end{tabular}

Table 1: The dimensions of a simple representation of a tanker geometry of overall length of $170 \mathrm{~m}$.

Firstly, flow visualisation studies were performed in a wind tunnel to understand the complexity of the flow to be modelled (Figure 8). A scaled 1:46 generic tanker model was placed in the low speed section of the Southampton $2.13 \mathrm{~m}$ by $1.52 \mathrm{~m}$ wind tunnel. At deck level a vortex was formed in front of the deck house block. Above the bridge top the air separated at the sharp leading edge and created a recirculation region close to the bridge top with accelerated air above. The decelerated region increases in depth with distance from the upwind leading edge and did not reattach to the bridge top.

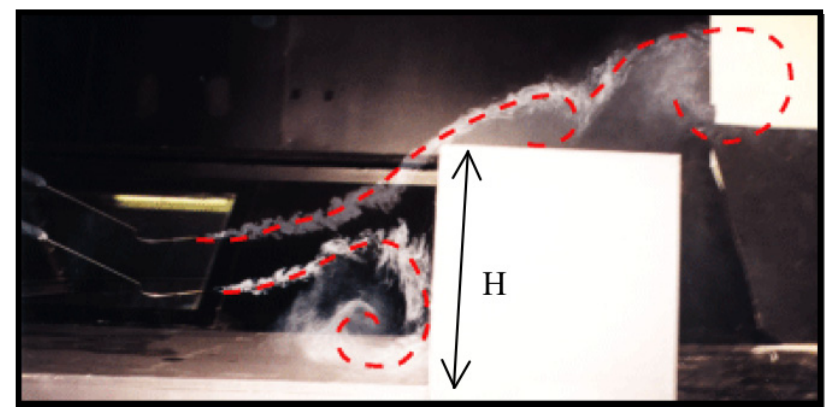

Figure 8: A wind tunnel study of the flow over the bridge of a simplified tanker/bulk carrier. The flow is from left to right.
CFD studies were performed over the same 1:46 scale tanker model (Figure 3). A normalised wind speed profile at a distance of $\mathrm{x} / \mathrm{H}=0.3$ back from the leading edge of the bridge is shown in Figure 9, where $\mathrm{H}$ is the bridge top to deck height. The wind speed was normalised by the free stream wind speed simulated from a second VECTIS simulation with no model present. Wind speeds from anemometers placed close to the bridge top (at heights of $\mathrm{z} / \mathrm{H}<0.2$ ) can be decelerated by up to $100 \%$ and may even reverse in direction. Above this decelerated region the wind speeds are accelerated by over $10 \%$ and return to within $2 \%$ of the free stream wind speed at a height of $\mathrm{z} / \mathrm{H}=2.5$.

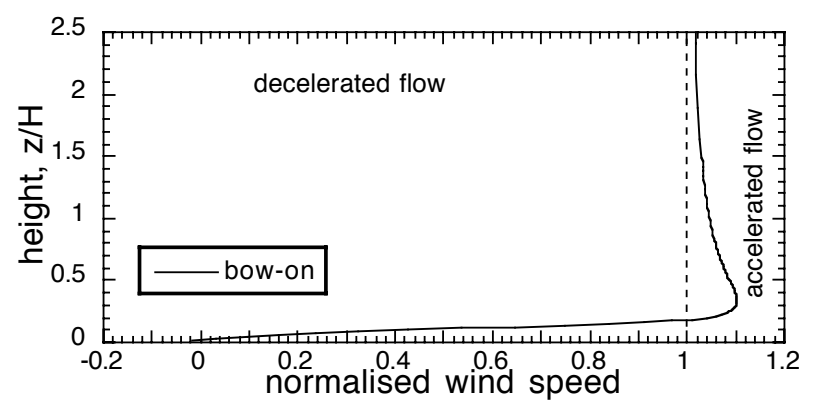

Figure 9: A vertical profile of the normalised wind speed above the bridge of the tanker (adapted from [12]).

\subsection{CONTAINER SHIPS}

A container ship geometry was made by adding an extra block to the tanker geometry in order to represent the containers loaded forwards of the deck house block. Moat [11] found that the large upwind obstacle of the containers influenced the downstream flow above the bridge. In addition, it is unknown what effect the irregular loading of the containers will have on the airflow across them and consequently the flow above the bridge. This will be the subject of future work.

\section{APPLICATION OF RESULTS}

Anemometers on research ships and VOS should be located as high as possible above the deck, ideally on a foremast in the bows of the ship. If the anemometer is to be located above the bridge of the ship, it should be placed as high as possible above the front edge. Previous studies suggest that instruments should be located at a distance of over three mast diameters from cylindrical masts and spars [26]. The airflow in front of platforms is generally decelerated; therefore, anemometers located on platforms should be sited above the platform rather than in front [12].

VOS vary a great deal in size and type and until recently the anemometer positions were unknown. With the recent inclusion of these ship parameters in the WMO Publication No. 47 metadata [25] the results from CFD models can be used to examine the effects of airflow distortion on the wind speed reports from anemometers on tankers and bulk carriers. 


\section{CONCLUSIONS}

Comparisons with independent wind tunnel data and with in situ wind speed measurements have determined that CFD is a valid research tool to investigate the mean air flow over ships. For anemometers located outside the wake of upstream obstacles the results agreed to within $4 \%$ (or better).

Wind speed measurements from anemometers on ships can be biased by the presence of the ships hull and superstructure. The size of the bias is dependent upon the anemometer position and the relative wind direction, i.e. the angle of the ship to the wind. Measurements from well-exposed anemometers on research ships may only be biased by about $10 \%$.

The mean flow above the bridge of typical tankers and bulk carriers is defined by flow separation at the upwind leading edge, with a decelerated region close to the bridge top. Wind speed measurements made from anemometers above the bridge can be biased high by over $10 \%$, or low by up to $100 \%$. Predicting and correcting the bias in wind speed measurements reported from fixed anemometers located on merchant ships participating in the VOS programme will be the subject of future work.

Anemometers on ships should be positioned as high as possible above the deck and if possible located in the bows of the ship. It is not recommended to locate anemometers directly in front of platforms or structures. Anemometers above the bridge of a merchant ship should be located as high and as far forewards as possible, ideally above the front edge of the bridge.

The design of a ship will affect the amount the airflow is distorted. A comparison of two research ships with different superstructure design has shown that a blocklike superstructure, close to anemometers located on the foremast in the bow of the ship, can significantly effect the wind speed measurements. If possible, it is recommended that the superstructure of research ships should be streamlined or located as far as possible from the foremast to reduce its influence on the upstream airflow.

\section{ACKNOWLEDGEMENTS}

The authors would like to thank Val Swail (Meteorological Service of Canada) and Dr. Dave Hosum (Woods Whole Oceanographic Institution, USA) for Partial Funding throughout this project.

\section{REFERENCES}

1. MOCTAR, O. E. and BERTRAM, V., 'Computation of viscous flow around fast ship superstructures', $24^{\text {th }}$ Symposium on Naval Hydrodynamics, Fukuoka, Japan, 2002, 68-77.
2. JIN, E., YOON, J. and KIM Y., 'A CFD based parametric study of the smoke behaviour of a typical merchant ship', Practical design of ships and other floating structures, Y-S Wu, W-C Cui and G-J Zhou (Ed.) Elsevier Science Ltd. 2001, 459 - 465.

3. TAI, T. C. and CARICO, D., 'Simulation of DD-963 ship airwake by Navier-Stokes method. J. of Aircraft, 32(6), 1995, 1399-1401.

4. CHENEY, B. T. and ZAN S. J., 'CFD code validation data and flow topology for the technical co-operation program AER-TP2 simple frigate shape'. National Research Council Canada, Institute for Aerospace Research, Canada, Report No. LTR-A-035, 1999, 32 pp.

5. KAHMA, K. K., and LEPPÄRANTA, M., 'On errors in wind speed observations on R/V Aranda', Geophysica, 17(1-2), 1981, 155-165.

6. YELLAND, M. J., MOAT, B. I., TAYLOR P. K., PASCAL, R. W., HUTCHINGS J. and CORNELL V. C., 'Wind stress measurements from the open ocean corrected for airflow distortion by the ship', J. of Phys. Oceanogr., 28(7), 1998, 1511-1526.

7. YELLAND, M. J., MOAT, B. I., PASCAL, R. W. and BERRY, D. I., 'CFD model estimates of the airflow over research ships and the impact on momentum flux measurements', J. of Atmos. and Ocean. Tech., 19(10), 2002, 1477-1499.

8. DUPUIS H., GUERIN, C., HAUSER, D., WEILL A., NACASS, P., DRENNAN, W. M., CLOCHE, S. and GRABER, H. C., 'Impact of flow distortion corrections on turbulent fluxes estimated by the inertial dissipation method during the FETCH experiment on $\mathrm{R} / \mathrm{V}$ L'Atalante', J. of Geophys. Res., 108(C3), 2003, 8064, doi: 10.1029/2001JC001075.

9. POPINET S., SMITH, M. and STEVENS, C., 'Experimental and numerical study of the turbulence characteristics of airflow around a research vessel', J. of Atmos. and Ocean. Tech., 21 (10), 2004, 1575-1589 pp.

10. POPINET, S, 'The GERRIS flow solver. Release 0.6.0. Freely available at http://gfs.sourceforge.net/ , 2003

11. MOAT, B. I., YELLAND, M. J., PASCAL, R.W. and MOLLAND, A. F., 'An overview of the airflow distortion at anemometer sites on ships', Accepted by the Int. J. of Climatology.

12. MOAT, B. I., YELLAND, M. J. and MOLLAND, A. F., 'Quantifying the airflow distortion over merchant ships: part II: application of model results', submitted to the J. of Atmos. and Ocean. Tech., 2005. 
13. RICARDO, 'VECTIS Computational Fluid Dynamics (Release 3.8) user manual', Ricardo Consulting Engineers Ltd., Shoreham-by-Sea, UK, 2004, $578 \mathrm{pp}$.

14. LAUNDER, B. E. and SPALDING D. B., 'The numerical computation of turbulent flows', Computer Meth. in Appl Mech. and Eng., 3, 1974, 269 - 289 pp.

15. YAKHOT, V., ORSZAG, S. A., THANGAM, S., GATSKI, T. B., and SPEZIALE, G., 'Development of turbulence models for shear flows by a double expansion technique', Physics of Fluids, A4(7), 1992, 1510-1520.

16. EASON, G., 'Improved Turbulence models for Computational Wind Engineering. PhD. Thesis, University of Nottingham, UK., 2000, 219 pp.

17. FEMSYS, 'FEMGV User manual', Femsys Ltd., Leicester, United Kingdom, 1992, 598 pp.

18. SMITH, S. D., 'Wind stress and heat flux over the Ocean in gale force winds', J. of Phys. Ocean., 10, 1980, 709-726.

19. Carrol, B, Personal communication, Ricardo Consulting Engineers, 2002.

20. MOAT, B. I., 'Quantifying the effects of airflow distortion on anemometer wind speed measurements from merchant ships' $P h D$. Thesis, University of Southampton, UK, 2003, 163 pp.

21. MARTINUZZI, R. and TROPEA, C., 'The flow around surface-mounted, prismatic obstacles placed in a fully developed channel flow', J. of Fluids Eng., 115, 1993, 85-92.

22. MINSON, A. J., WOOD, C. J., and BELCHER, R. E., 'Experimental velocity measurements for CFD validation', J. of Wind Eng. and Ind. Aero., 58, 1995, 205-215.

23. NEW, A., and CO-AUTHORS, 'RRS Charles Darwin Cruise $141,1^{\text {st }}$ June $-11^{\text {th }}$ July 2002 Satellite Calibration and Interior Physics of the Indian Ocean: SCIPIO'. SOC Cruise Report No. 41, Southampton Oceanography Centre, Southampton, UK. 2003.

24. MOAT, B. I., YELLAND, M. J. and MOLLAND, A. F., 'Quantifying the airflow distortion over merchant ships: part I: validation of CFD model', submitted to the J. of Atmos. and Ocean. Tech., 2005.

25. KENT, E. C., WOODRUFF, S. D. and BERRY, D. I., 'WMO publication of metadata and an assessment of observation heights in ICOADS', submitted to the $J$. of Atmos. and Ocean. Tech., 2005.
26. GILL, G. C., OLSSON, L. E., SELA, J. S. and SUDA, M., 'Accuracy of wind measurements on towers and stacks', Bull. Amer. Meteor. Soc., 48, 1967, 665-674.

\section{AUTHORS' BIOGRAPHIES}

Ben Moat holds the current position of Research Fellow at the Southampton Oceanography Centre, UK. He is responsible for the CFD ship modelling.

Margaret Yelland holds the current position of Senior Scientific Officer at the Southampton Oceanography Centre, UK. She has overall responsibility for the project. Anthony Molland holds the current position of Professor of Ship Design at the School of Engineering Sciences, University of Southampton, UK.

Robin Pascal is an Engineer at the Southampton Oceanography Centre, UK. His responsibilities include the implementation of ship based meteorological measurements. 